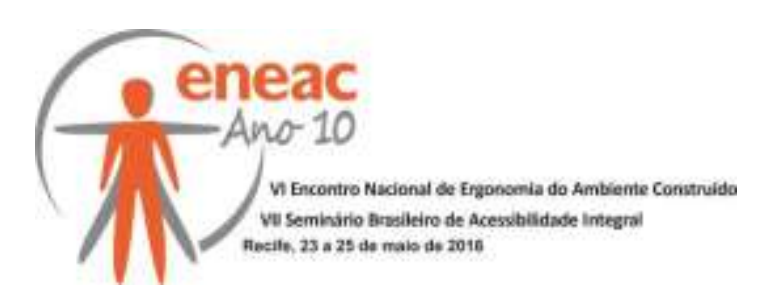

\title{
QUALIDADE AMBIENTAL EM ESPAÇOS LIVRES: UMA AVALIAÇÃO NO CENTRO DE VIVÊNCIA DO CAMPUS I DA UFPB
}

\author{
SARMENTO, Bruna Ramalho (1); \\ ELALI, Gleice Azambuja (2) \\ (1) LACESSE, UFPB / PPGAU, UFRN, Doutoranda em Arquitetura e Urbanismo \\ e-mail:brunarsarmento@hotmail.com \\ (2) DArq/PPGAU, UFRN, Doutora em Arquitetura e Urbanismo \\ e-mail:gleiceae@gmail.com
}

\begin{abstract}
RESUMO
Este artigo concentra a atenção em um dos principais espaços livres do campus I da UFPB, o Centro de Vivência (CV), a fim de avaliar a qualidade ambiental (QA) que proporciona aos seus usuários. A avaliação recorreu à elaboração e aplicação de uma Planilha de Avaliação da QA, preenchida de modo a proporcionar um diagnóstico da condição ambiental desse local, a partir de seus aspectos positivos e negativos. Dada à representatividade do CV no campus acredita-se que a avaliação será de grande valia para a Instituição, podendo contribuir para a criação de parâmetros para modificação de outros espaços do campus.
\end{abstract}

Palavras-chave: qualidade ambiental; espaços livres; campus universitário.

\begin{abstract}
This article focuses attention on one of the main open spaces of UFPB's campus I, the Experience Center (EC) in order to assess the environmental quality (EQ) that provides its users. The evaluation resorted to the development and implementation of an EQ assessment sheet, filled in order to provide a diagnosis of the environmental condition of this place, from its positive and negative aspects. Given the representativeness of $E C$ on campus it is believed that the evaluation will be of great value to the institution, contributing to the creation of parameters for modifying other campus spaces.
\end{abstract}

Keywords: environmental quality; open spaces; university campus.

\section{INTRODUÇÃO}

Nos países desenvolvidos todo produto colocado em uso, incluindo o ambiente construído, precisa passar por avaliações sistemáticas de controle de qualidade, visando atender a necessidade de seus usuários. Ornstein e Roméro (1992) alertam que, no entanto, no Brasil essa prática não tem se efetivado; ao contrário, há a repetição sucessiva de produtos que não satisfazem o usuário, especialmente edificações públicas colocadas em uso a partir da década de 1950. Reforçando essa afirmativa a partir de um ponto de vista mais recente, Nasar et al (2007 apud KOWALTOWSKI; MOREIRA; DELIBERADOR, 2012), demonstram que os maiores problemas destas obras públicas estão relacionados à sua funcionalidade, à navegabilidade do espaço, à acessibilidade, às condições de conforto ambiental e estética, 


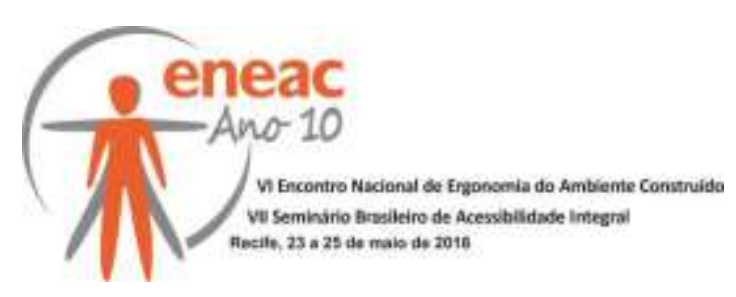

destacando que as críticas dos usuários revelam claras divergências entre o ponto de vista de projetistas/planejadores e do público em geral.

Nas Instituições Federais de Ensino Superior (IFES) brasileiras esse tipo de descuido reduz a vida do ambiente construído e pode induzir a deterioração das relações humanas, que acontecem em espaços também deteriorados. Essas evidências indicam a necessidade de criar bancos de dados relacionados à produção e uso dos ambientes universitários, investigando seus aspectos positivos e negativos e realimentando seu processo projetual. Esse tipo de estudo pode ser desenvolvido através de avaliações pós-ocupação (APO) do ambiente construído, que se constituem uma forma eficiente de controle de qualidade ou de realimentação de projetos semelhantes (ORNSTEIN, ROMÉRO, 1992; ROMÉRO, ORNSTEIN, 2003; PREISER, VISCHER, 2005; RHEIGANTZ et al, 2009).

Direcionando mais especificamente para o ambiente universitário, Bins Ely e Ghizi (2006) comentam que os campi são bons representantes da dinâmica do ambiente construído, visto que recebem uma grande diversidade de usuários, seja relativa à idade, cultura, status social ou mesmo habilidades físicas, sensoriais e cognitivas. Segundo as autoras, esta diversidade deve ser respeitada, pois, desde que reconhecida e aceita, enriquece e humaniza a comunidade acadêmica, devendo ser incentivada/valorizada, tanto em espaços internos quanto na área livre.

Inserindo-se ativamente nas cidades, os campi podem ser entendidos a partir de uma definição ampla de espaço urbano enquanto "um complexo de espaços edificados e espaços livres, ambos resultantes de ações humanas condicionadas pelas concepções sociais e culturais ao longo do tempo" (SÁ CARNEIRO; MESQUITA, 2000, p.24). Nesse contexto compreende-se espaço livre (EL) como o somatório de todas as áreas não ocupadas por um volume edificado, externas às edificações e às quais as pessoas têm acesso, quer apresentem vegetação ou não (MAGNOLI, 2006). Portanto, toda cidade possui um sistema de espaços livres (SEL) cuja formação é devida às relações dinâmicas entre suas áreas livres de edificações em oposição aos ambientes edificados, quer tais espaços sejam conectados fisicamente ou não, planejados ou não (CUSTÓDIO et al, 2011). Nesse sentido, o conceito de sistema exprime ao mesmo tempo unidade, multiplicidade, totalidade, diversidade, organização e complexidade, se apresentando como um objeto complexo, suficientemente fechado, pois caso contrário não se constituiria, mas também suficientemente aberto, uma vez que estabelece relações com outros sistemas (MORIN, 2008). Ou seja, entende-se como SEL urbanos os elementos e as relações que formam o conjunto de todos os ELs de um determinado recorte urbano, da escala intraurbana à regional (QUEIROGA et al, 2011).

Com relação aos espaços livres (ELs) de campus, Wong et al (2009 apud KOWALTOWSKI; MOREIRA; DELIBERADOR, 2012) demonstram que devem: propiciar impacto estético positivo; estar adaptados ao contexto; ser convidativos e confortáveis; atender às necessidades; mostrarem-se responsáveis ambientalmente. Para alcançar tais atributos os autores indicam que o projeto desses espaços precisa incorporar de forma ponderada aspectos de estética, funcionalidade, economia e viabilidade construtiva, expressos tanto pelo conhecimento técnico, como pelo atendimento aos anseios dos usuários. De modo a proporcionar qualidade ambiental e, consequentemente, um convívio agradável para a comunidade universitária.

Nesse quadro, este artigo concentra a atenção em um dos principais ELs do campus I da Universidade Federal da Paraíba (UFPB), o Centro de Vivência (CV), a fim de avaliar a qualidade ambiental que este proporciona a seus usuários. O trabalho realizado é parte de uma tese em desenvolvimento que realizará estudos em IFES (título provisório: $A$ reestruturação na ocupação dos ELs nos campi centrais da UFPB e UFRN: um estudo sob a ótica da Avaliação Pós-Ocupação). Embora na tese seja utilizada uma estratégia de 


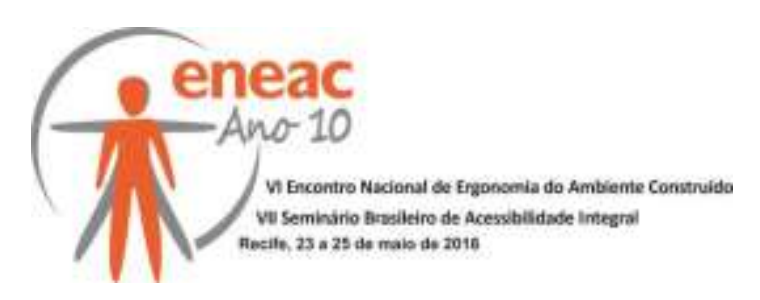

pesquisa multimétodos (SOMMER; SOMMER, 2002; GUNTHER; ELALI; PINHEIRO, 2008), esse artigo enfatiza o diagnóstico técnico.

\section{MÉTODO}

A avaliação recorreu a uma Planilha de Avaliação da QA elaborada especificamente para esta atividade, e voltada para um diagnóstico da condição ambiental do local a partir de seus aspectos positivos e negativos. A avaliação foi realizada em novembro de 2015 . A planilha contempla cinco dimensões - Ambiental; Segurança; Mobilidade Interna/Estacionamento; Mobilidade Campus-Cidade; Serviços de Apoio -, cada uma detalhada a partir de indicadores definidos a partir da literatura nesse campo (ver exemplo de um detalhe na Figura1).

Figura 1 - Detalhe da Planilha de Avaliação da Qualidade Ambiental.

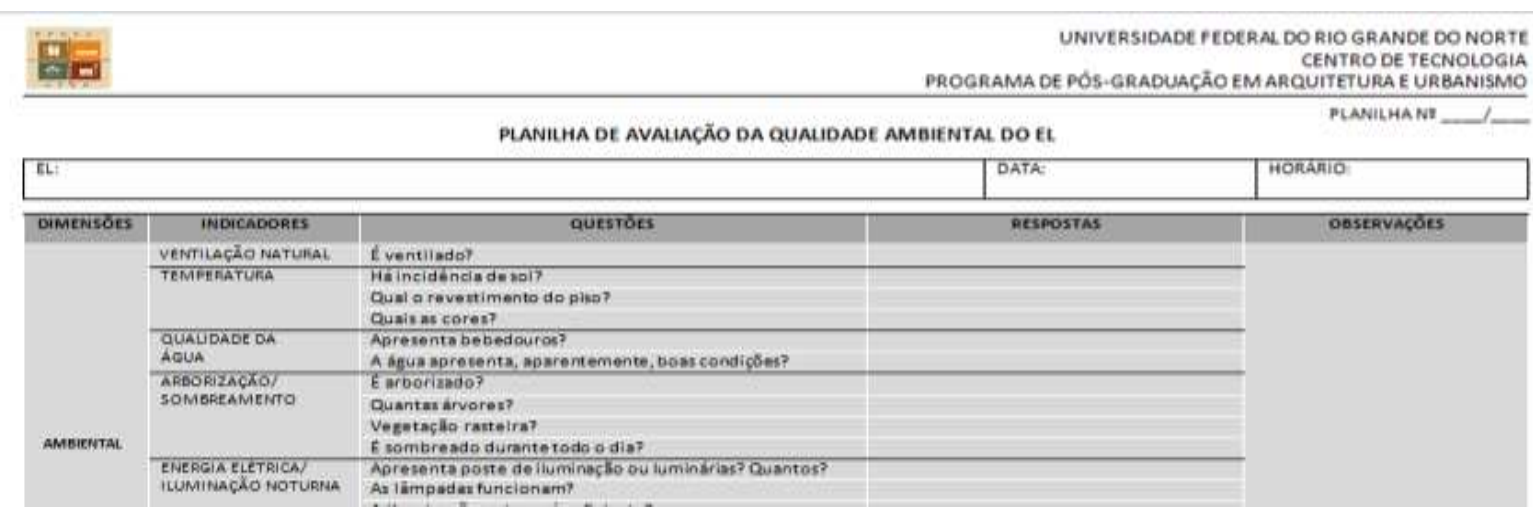

Fonte: Elaboração própria.

Ao longo da aplicação da planilha foram utilizadas técnicas complementares, como: Observações/Análises de Desempenho Físico, Checklist e Visitas Especificas, descritas conforme segue:

- Observações/Análises de Desempenho Físico - Trata-se da avaliação técnica realizada in loco, para verificação de possíveis problemas físico-construtivos nas áreas estudadas. Tais observações, análises e avaliações foram realizadas primeiramente de forma expedita (walkthrough), para em seguida serem realizadas de forma detalhada.

- Checklist - Elaboração de uma lista de aspectos a serem verificados no EL, a ser analisada/preenchida por meio de uma ou mais vistorias técnicas, relativas à condição física do EL, sendo essencial para que a reunião das características atuais do lugar. Conforme Issa, Poltronieri e Ornstein (2008), este instrumento também objetiva verificar, de forma qualitativa, a adequação de tais espaços às determinadas exigências por normas e diretrizes, bem como às necessidades dos usuários.

- Visitas Específicas - No decorrer de toda a pesquisa foram feitas visitas a setores do campus (Prefeitura Universitária, Setor de Segurança, Comissão de Gestão Ambiental), no sentido de obter informações para responder, em especial, às dimensões: Segurança; Mobilidade interna/estacionamento; Mobilidade campus-cidade; Serviços de Apoio. 


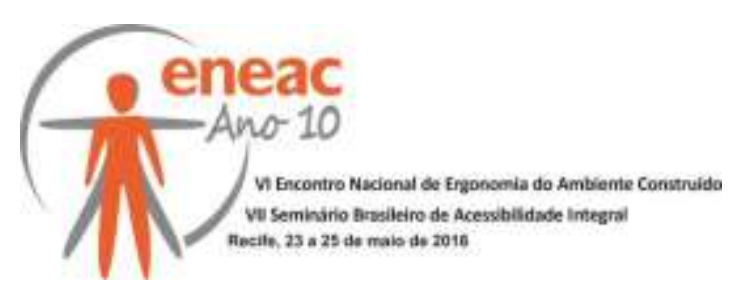

\section{CONTEXTO EM ESTUDO: O CAMPUS I DA UFPB E SEU CENTRO DE VIVÊNCIA}

O campus I da UFPB está localizado no bairro Castelo Branco, Zona Leste da cidade de João Pessoa, PB. Limita-se com a Mata do Buraquinho (Mata Atlântica remanescente com uma extensa área de preservação permanente - APP), o bairro dos Bancários e a Rodovia Federal BR 230 (Figura 2). Ele foi criado em 1955 e federalizado em 1960, possui uma área total de 161,75 ha, aos quais estão incorporados 03 núcleos de preservação permanente, resultando 117,8 ha de espaços ocupáveis, que congregam 97 cursos de graduação (em 2012), distribuídos em 13 centros de ensino. Conta, ainda, com setores de vivência, administrativos, de serviços e esportivo, com grandes áreas construídas e bolsões de Mata Atlântica preservada (SARMENTO, 2012).

Figura 2 - Mapa do Campus I da UFPB inserido na malha urbana de João Pessoa-PB, combinado com imagem aérea de inserção do campus I no bairro Castelo Branco e seus limites.

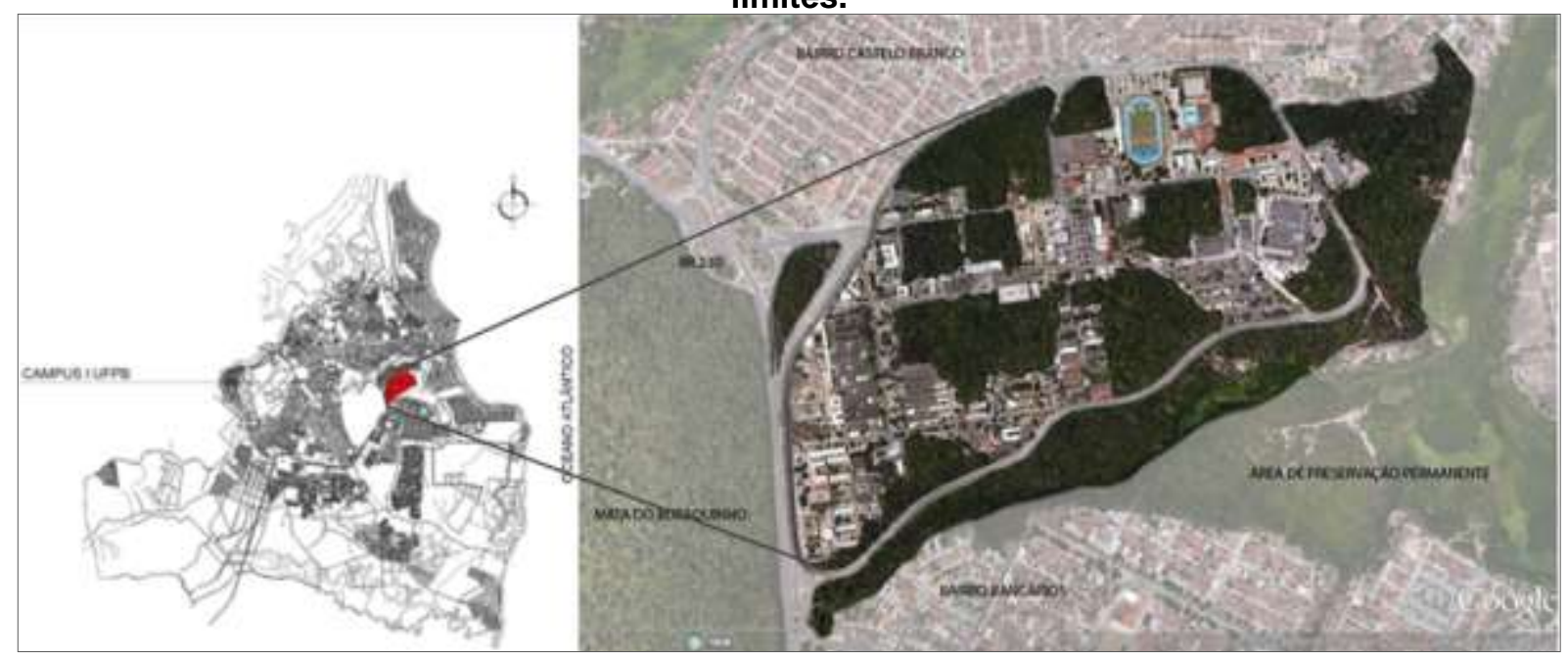

Fonte: Costa et al (2009) (imagem JP); Google Earth (2016) (imagem campus), modificada pela autora.

O campus I apresenta topografia majoritariamente plana (com alguma declividade a Leste, próximo ao Hospital Universitário) e 9 acessos: 5 de uso misto (para pedestres e veículos) e providos de guaritas; 4 exclusivos para pedestres, próximo a pontos de transporte coletivo. Os centros de ensino são interligados por calçadas, passarelas térreas e cobertas e faixas de pedestres. Seu processo de ocupação evoluiu gradativamente a partir da década de 1970 , tendo se acentuado nos anos 2000, com o advento do Programa REUNI, quando a UFPB intensificou obras e criou novos cursos (UFPB, 2011); entre 2007 e 2012 o número de estudantes de graduação aumentou em $72 \%$, o quadro de docentes cresceu $25 \%$ e o de servidores em 18\% (UFPB, 2007). O Plano REUNI-UFPB (UFPB, 2007) previa a construção de $34.125 \mathrm{~m}^{2}$ de novas edificações no campus I e reforma de $12.205 \mathrm{~m}^{2}$, ações estruturantes que serviram de base física à implantação de 30 novos cursos.

Em se tratando dos serviços de apoio, para atender toda essa demanda de usuários o campus I conta com um SEL considerável e diversificado, principalmente no que se refere a atividades de práticas sociais: pátios; jardins; praças; gazebos; quadras; campos; piscinas; anfiteatros; e CV. Este último (objeto de estudo deste artigo) é apontado por $15 \%$ dos usuários do campus como sendo o EL mais frequentado por eles (SARMENTO; ELALI, 2015). Sarmento (2012), apoiando-se na sintaxe espacial, indica ainda que a edificação está na área mais integrada do espaço urbano do campus I da UFPB, o núcleo central, que congrega os edifícios do Restaurante Universitário (RU), da Biblioteca Central (BC), do CV e 


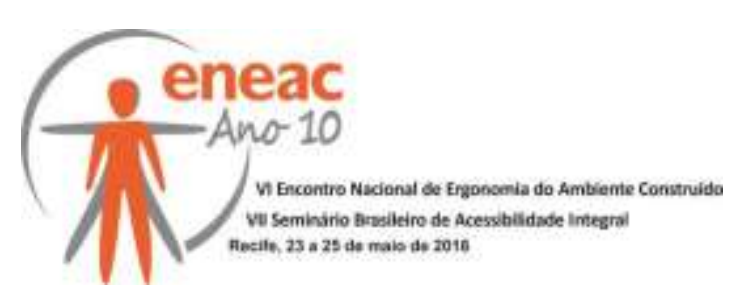

da Reitoria (Figura 3), que indicam maiores níveis de acessibilidade. Desse modo, pela representatividade do CV no campus I da UFPB acredita-se ser de grande valia para a instituição a avaliação da QA do local.

Segundo Coutinho et al (2010), o CV (Figura 4) do campus I da UFPB foi projetado pelos arquitetos Armando Carvalho e Hélio Costa Lima e inaugurado em 1979, estando localizado em sua área central (Figura 3), ladeado pelo Restaurante Universitário (RU), pela Cooperativa Cultural e Distribuidora de Material Escolar da UFPB de Responsabilidade LTDA (CODISMA) e a Cooperativa de Economia e Crédito Mútuo dos Servidores das Instituições Públicas de Ensino Superior do Estado da Paraíba LTDA (CREDUNI - em construção). Trata-se de um edifício aberto e de uso comum a todos os centros, que representa um dos principais ELs do campus.

Figura 3 - Mapa do Campus I da UFPB com o trecho do CV e seu entorno imediato em destaque.

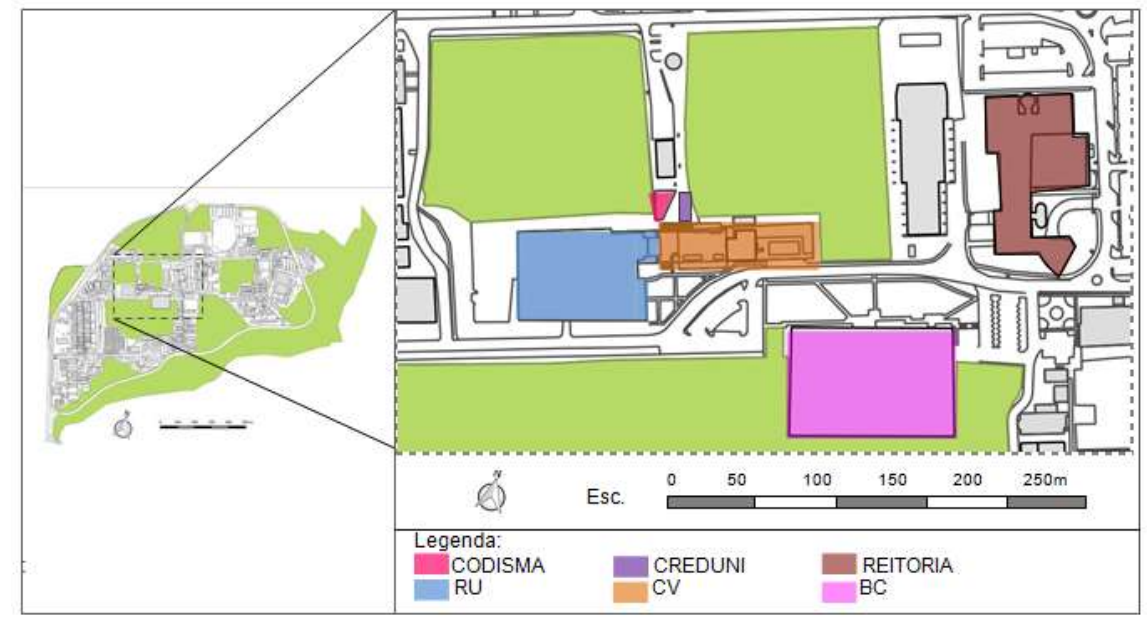

Fonte: Pesquisa de campo sobre mapa base cedido pela Prefeitura Universitária da UFPB.

Figura 4 - Imagem do CV.

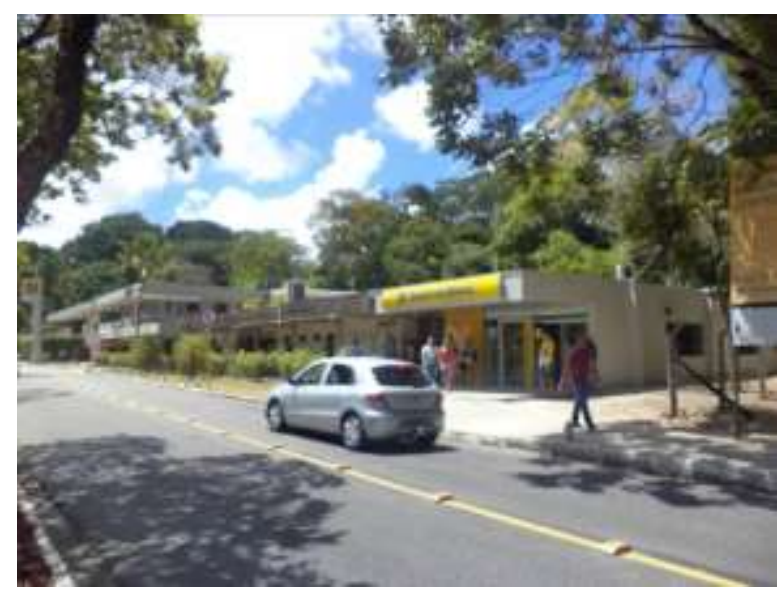

Fonte: Pesquisa de campo.

\section{BREVE DIAGNÓSTICO DO CV}

O CV pode ser visto a uma distância considerável, pela sua dimensão, porém, quando se está longe não é possível saber o que acontece nele, apenas, muitas vezes, se ouve o som 


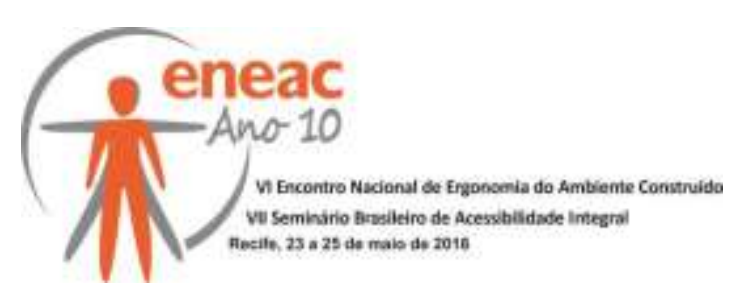

de músicas ou vozes, dependendo da atividade exercida no momento (reuniões sindicais, feiras, apresentações artísticas, dentre as mais comuns).

No local há muitos pontos comerciais (funcionando manhã e tarde) (Figura 5): duas bancas, sendo uma delas uma banca de revistas e outra uma lanchonete; duas papelarias; duas xérox; um ponto de recarga de crédito de passagem em transporte público municipal; duas agências bancárias (sendo uma delas apenas uma sala); um sebo de livros; uma lanchonete/restaurante; um correio; uma farmácia (sem funcionamento); uma sala do Diretório Estudantil (DCE); e dois pontos comerciais fechados. Há, ainda, muito comércio informal no local, em sua maioria do gênero alimentício. Alguns dos pontos comerciais formais interferem na circulação dos usuários, em especial os que distribuem mobiliário para atender aos clientes (Figura 6a), e o comércio informal (Figura 6b), que geralmente se localiza em trechos de grande fluxo de pedestres. Apesar de uma das agências bancárias (recentemente reformada e ampliada) instalada no CV ocupar uma extensa área do edifício, muitos usuários aguardam a abertura da agência, o que causa filas quase sempre uma hora antes de sua abertura. Muitas filas também são comuns na entrada do RU (onde há muitos bancos para espera), especialmente no horário do almoço, e no posto de recarga de crédito em passagens. A única farmácia do campus I da UFPB se encontra fechada e sem perspectiva de retorno de suas atividades. No pavimento superior do EL funciona a Associação dos Docentes de Universidades Federais da Paraíba (ADUF-PB); no nível térreo também há um desnível, vencido por um lance de escadas (Figura $6 \mathrm{c}$ ). Além da mencionada aglomeração nas filas, verificam-se ainda como pontos de encontro e convívio as lanchonetes do EL, onde muitos usuários se reúnem para lanchar, conversar, conviver.

Figura 5 - Planta do térreo e primeiro pavimento do CV com destaque para os usos do local.

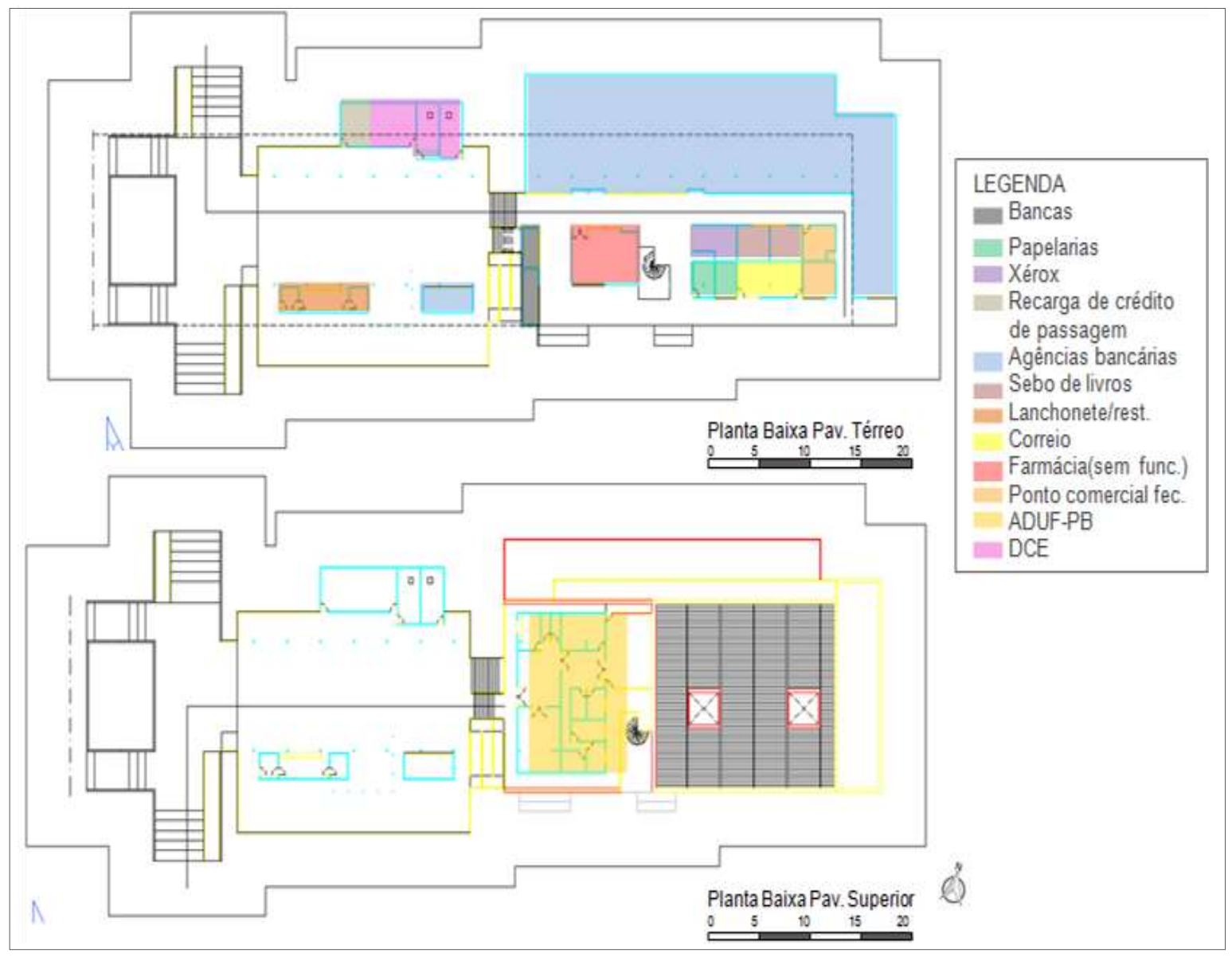

Fonte: Plantas cedidas pelos arquitetos Marco Coutinho e Wylnna Vidal, modificada pela autora. 


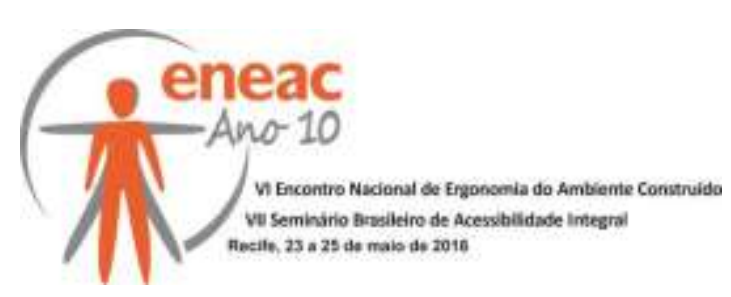

Figura 6 - a) Imagem de mobiliário móvel obstruindo parte da área livre do CV; b) Comércio informal; Lances de escada de acesso do CV.

a)

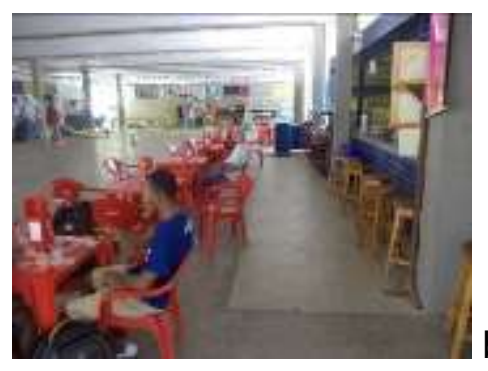

b)
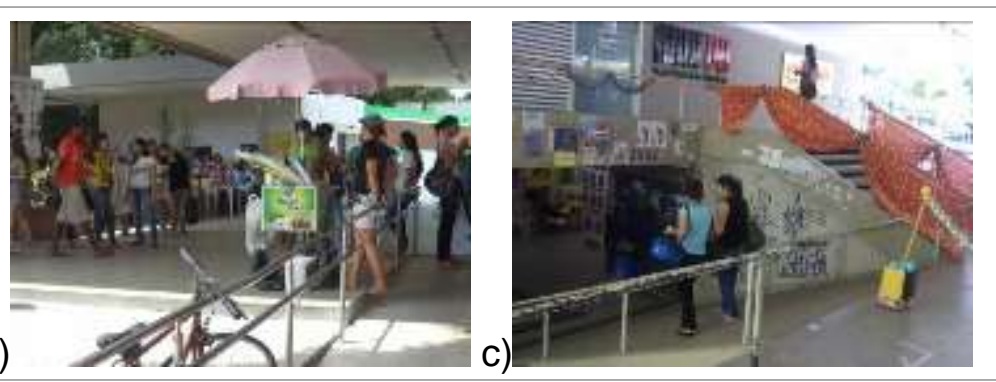

Fonte: Pesquisa de campo.

O EL é propício à ocorrência de: apresentações culturais, as quais acontecem com frequência; a leitura (dependendo do horário); e a prática de atividades físicas (são muitas as apresentações de dança no local). Destaca-se que durante a análise estava ocorrendo no local uma apresentação organizada pelo curso de Educação Física da UFPB, na qual estudantes de escolas públicas municipais apresentam danças folclóricas típicas da região Nordeste, o evento acontece a cada três meses no CV (Figura 7a). Para tanto, a organização cerca parte do EL disponível e a escada de acesso a ADUF-PB, o que causa considerável obstrução da área comum, interrompendo rotas de circulação dos usuários. Essa situação foi identificada especialmente quando um usuário com deficiência visual, funcionário da BC (edificação próxima ao EL), tentava circular, mas foi necessário pedir ajuda, pois o caminho que ele costuma seguir estava interrompido pela área cercada para a apresentação.

São muitas as pessoas que utilizam o EL, apresentando um equilíbrio entre homens e mulheres, de faixas etárias variadas, mas com predomínio de jovens em grupo. A maioria das pessoas que utilizam o EL sozinhas está apenas passando pela área, pois os que permanecem quase sempre estão em grupo.

O CV é, em sua maioria, coberto (Figura 7b), o que minimiza a incidência do sol, que foi identificada apenas em poucos trechos (principalmente no início da tarde): área atrás da lanchonete (Figura 7c) e jardim junto aos bancos na entrada do RU.

A ventilação, iluminação e a acessibilidade do CV foram comprometidas após a construção de duas edificações (Figura 7d - Codisma do lado esquerdo e Creduni do lado direito), que reduziram um dos acessos ao local.

Figura 7 - a) Imagem do CV no momento de uma apresentação artística; b) Imagem do CV, em sua maioria coberto.

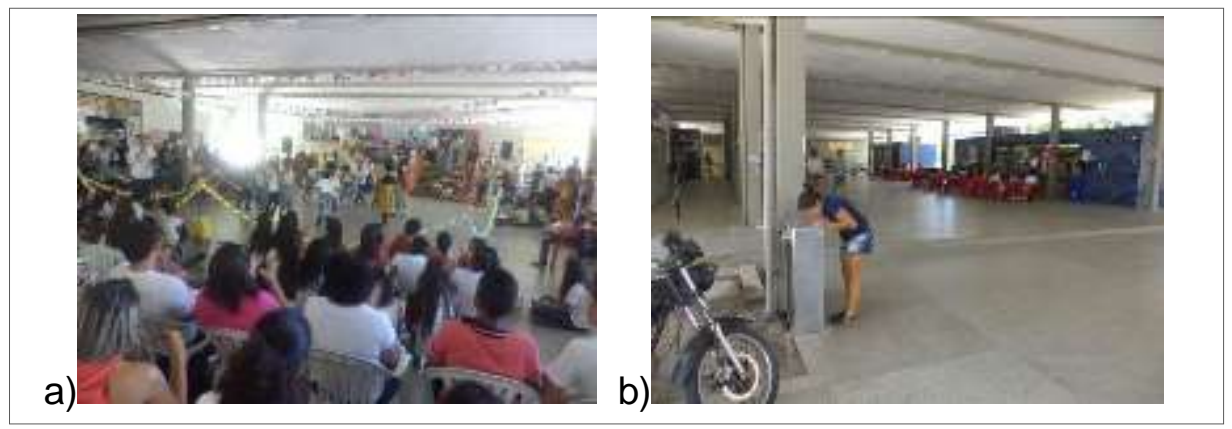

Fonte: Pesquisa de campo. 


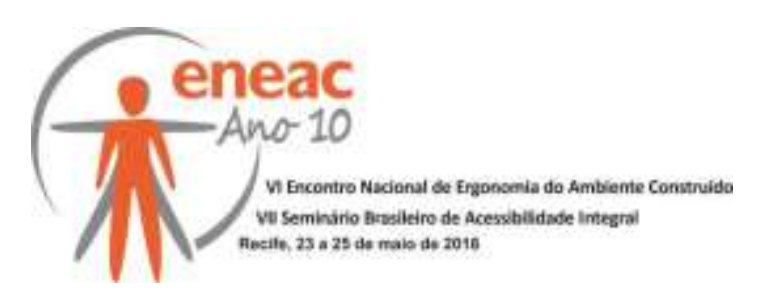

Figura 7 (continuação) - c) Imagem da área com incidência de sol; d) Imagem de um dos acessos do CV ocupados por novas edificações

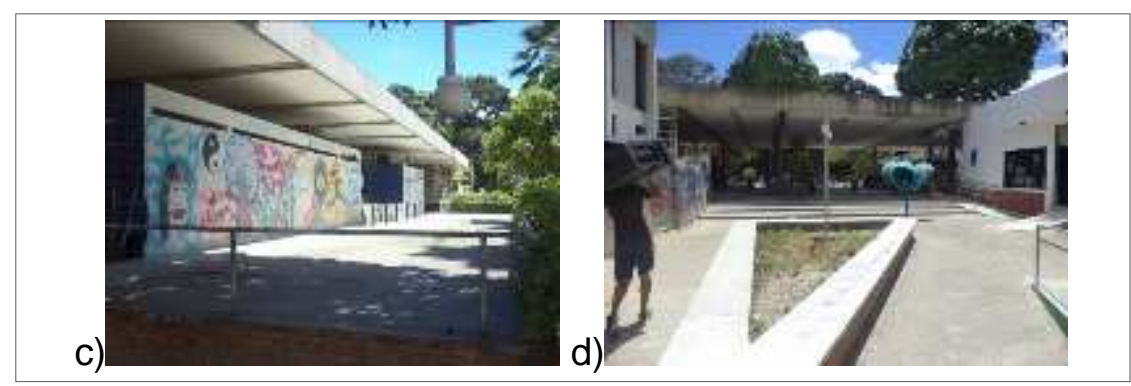

Fonte: Pesquisa de campo.

Quanto à ventilação, muitos comerciantes informaram que esta foi reduzida após as novas construções e reformas próximas e no local. Em conversa com o dono do sebo de livros (comércio que hoje se encontra em um corredor voltado para uma parede 'cega') (Figura 8a), soube-se que na área, que foi utilizada para a ampliação de uma agência bancária, antes funcionava uma livraria universitária, uma lanchonete e uma área aberta voltada para a APP, mas a agência ocupou todo esse espaço. E o corredor, que era bem ventilado, é hoje ocupado por motocicletas, que utilizam a área para estacionar (Figura 8b).

O CV é pouco arborizado, com a inserção de áreas ajardinadas (apenas com espécies de pequeno porte, em sua maioria), mas em parte de seu entorno há uma extensa APP.

O EL é fonte de ruído, pois se verifica muitas pessoas circulando, conversando, preparando alimentos na lanchonete, além de operários nas obras do entorno, que emitem muito barulho; o que leva as pessoas a elevarem um pouco a voz em uma conversação.

Especificamente sobre a acessibilidade, o EL tem rampas de acesso com corrimão, para acessar tanto o térreo quanto o primeiro piso (Figuras $8 \mathrm{c}$ e $8 \mathrm{~d}$ ) e calçada na área da fachada, que foi contemplada com um trecho de rota acessível (Figura 8e); porém apresenta também desníveis acentuados, falta de sinalização e quebras no piso; fatores que comprometem a mobilidade do usuário. A calçada tanto na fachada frontal, quanto posterior, permitem o acesso a edificações próximas, proporcionando uma continuidade no percurso. Em uma delas (fachada frontal) é necessário atravessar uma via (com faixa de pedestre, mas sem sinal sonoro) para acessar a BC (trecho com rota acessível) (Figura 8f); e na fachada posterior a calçada interliga o CV a Codisma, ao edifício do DCE e a Capela. As calçadas existentes, em especial a frontal, permitem a circulação do usuário, mas registrase dificuldade na mobilidade do usuário com deficiência, pois muitos circulam pelo campus quase sempre acompanhados, o que foi verificado durante a análise, quando um usuário cadeirante atravessava a via com ajuda de um acompanhante (Figura 8f).

O tempo médio de deslocamento para a edificação mais próxima $(\mathrm{BC})$ é de $2,10 \mathrm{~min}$. Esse percurso é facilitado pela existência da rota acessível; mas com constante presença de barreiras atitudinais (motocicletas estacionadas) no percurso. Apesar disso, não registramse acidentes entre veículos ou atropelamentos nas vias próximas, acredita-se que a faixa de pedestre que liga o EL ao estacionamento contribui para essa questão. 


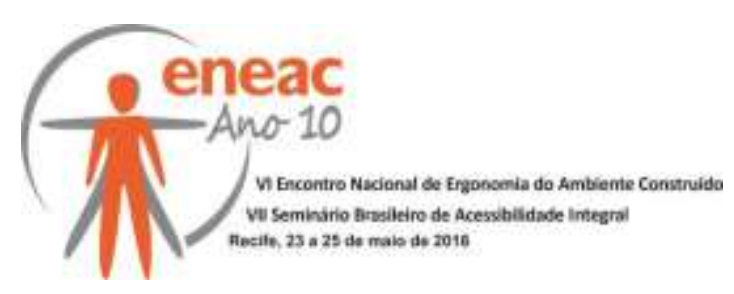

Figura 8 - a) Imagem do corredor onde está localizado o Sebo de Livros; b) Imagem de motos estacionadas no corredor; c) Rampa e escada de acesso ao CV; d) Rampa de acesso ao pavimento superior do CV; e) Rota acessível na calçada frontal do CV; f) Usuário cadeirante atravessando na faixa de pedestre junto ao $\mathrm{CV}$.

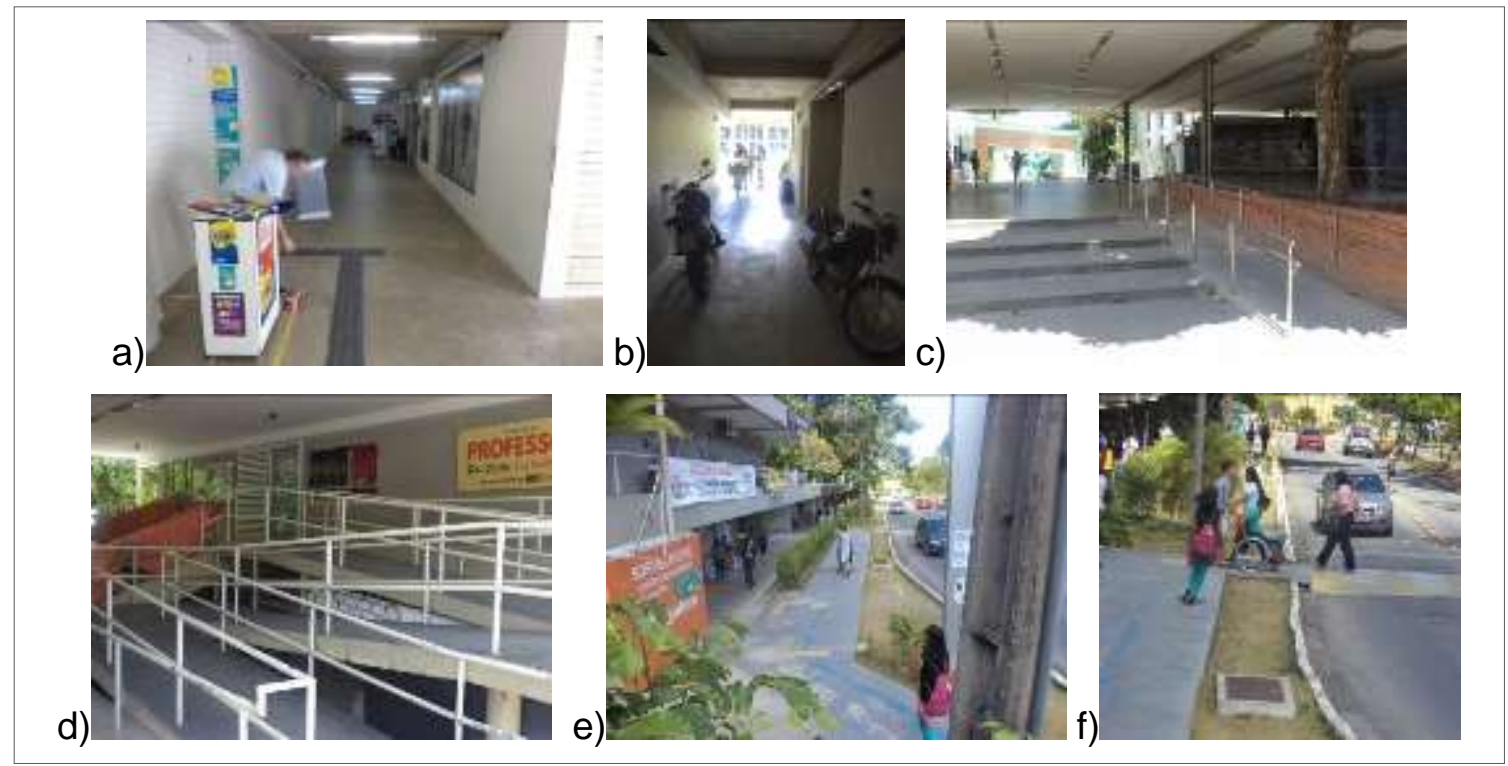

Fonte: Pesquisa de campo.

Não há semáforo próximo ao EL, mas a via existente, apenas junto à fachada frontal, interliga as edificações e os ELs próximos. Verifica-se a necessidade de uma área de carga e descarga junto ao EL, pois diariamente são feitas entregas no local em veículos estacionados em um dos lados da via (Figura 8a), que é de mão dupla e de tráfego intenso, o que pode ocasionar acidentes. Na frente do EL, próximo a faixa de pedestres, localiza-se ainda a área de entrada e saída de veículos do estacionamento.

É possível chegar ao EL por diversos meios de transporte: carro, bicicleta, motocicleta, caminhando ou de ônibus; no caso deste último o acesso é dificultado, pois, pela localização central do EL no campus, o usuário tem que percorrer trechos de calçadas e passarelas para se chegar a uma das paradas de ônibus do entorno da UFPB; já para usuários de veículos a dificuldade maior está em conseguir vaga no estacionamento, pois este não está mais suprindo a demanda do local, o que tem levado muitos usuários a procurar outros estacionamentos próximos, mas apesar disso ele conta com uma vaga acessível, com rampa de acesso à calçada, e faixa de pedestre que interliga o estacionamento a calçada do CV; para quem utiliza motocicleta ou bicicleta também há dificuldade, pois estes veículos não têm estacionamento específico, o que leva muitos usuários a estacionar em local irregular (Figura 8b), quase sempre obstruindo parte da circulação de pedestres (Figura 8c).

Figura 8 - a) Imagem de veículo estacionado para realizar carga e descarga no CV; b)Bicicletas estacionadas no corrimão; c)Motocicleta estacionada na circulação.

a)

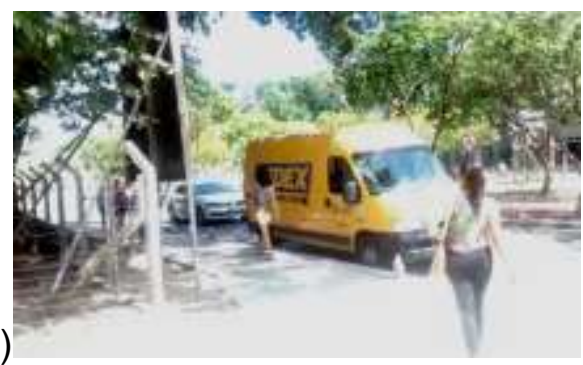

b)

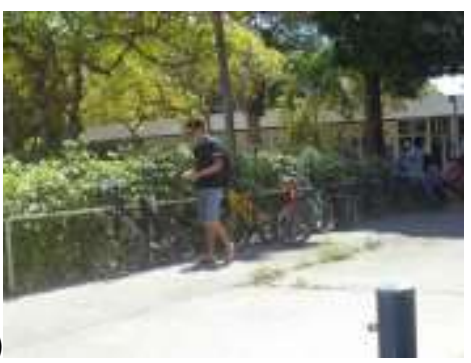

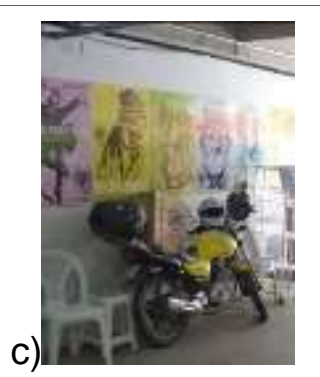

Fonte: Pesquisa de campo. 


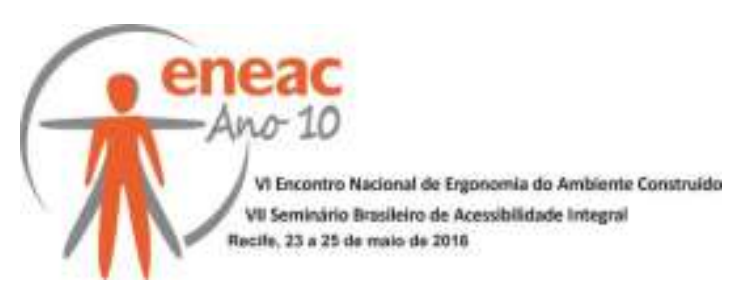

Há mobiliário urbano instalado no EL: diversos bancos fixos, dois bebedouros (com vazamento e bicas quebradas, porém ainda em uso) (Figura 9a); quatro telefones públicos (um junto à lanchonete/restaurante e três no entorno imediato). Porém, este mobiliário não supre a necessidade local, pois são muitas as mesas e cadeiras móveis espalhadas junto às lanchonetes, os bancos fixos também se concentram em um único trecho do $E L$, deixando o restante da área deficiente de espaços de apoio. Estes bancos, por estarem próximo a uma área descoberta, no início da tarde recebem a incidência direta do sol (Figura 9b), o que impossibilita o uso, visto que a região conta com temperaturas muito altas, principalmente nesse horário. Apesar de no local existir apenas seis lixeiras, sendo três verdes (lixo reciclável) e três azuis (lixo comum) e algumas junto às lanchonetes, sobre a limpeza podese dizer que a primeira impressão é regular, pois não se identifica acúmulo de lixo de pequeno porte no EL, que conta com uma equipe de limpeza (que realiza duas varrições diárias, uma manhã e outra a tarde) e comerciantes para mantê-lo. Mas a situação muda quando verificada a área próxima às obras, pois estas tem gerado entulho acumulado no EL (Figura 9c) e seu entorno. A sinalização da área se resumiu a apenas as placas nos pontos comerciais e na ADUF-PB. O principal ponto de referência no EL é o próprio EL ou os serviços que ele agrega, em especial, os que se localizam na fachada do local.

Não há índices de assaltos a pessoas na área, mas há traços de danos ao patrimônio, sendo o principal deles as pichações. Não se identifica a presença de vigilante fixo no EL, mas apenas no momento do almoço quatro desses profissionais se localizaram na entrada do $R U$, sendo dois em cada porta, pois já houve situações de tumulto nesse local, que é uma edificação anexa ao EL. Durante a noite uma das comerciantes informou que há um vigilante no local. Apesar do EL não ter câmeras de segurança ou a presença de um gestor permanente, são muitos os comerciantes trabalhando e observando diariamente a área.

De modo geral, o EL não apresenta boa manutenção, pois fatores negativos foram identificados: restos de cartazes nas paredes e pilares, infiltrações no teto e paredes (Figuras 9d e 9e), teto empoeirado, entulho de obra acumulado, pichações (Figura 9f), luminárias quebradas, além de muitas lâmpadas queimadas.

Figura 9 - Aspectos negativos detectados.

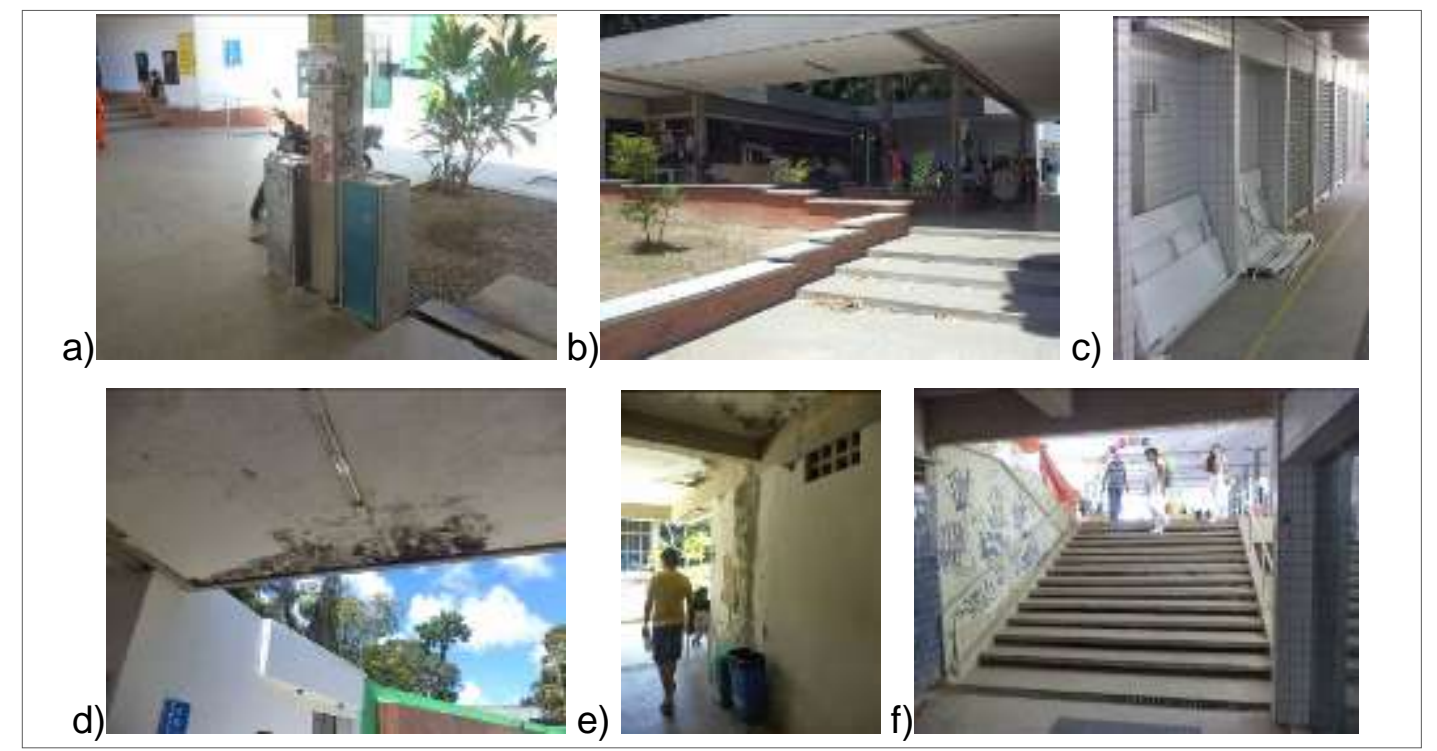

Fonte: Pesquisa de campo. 


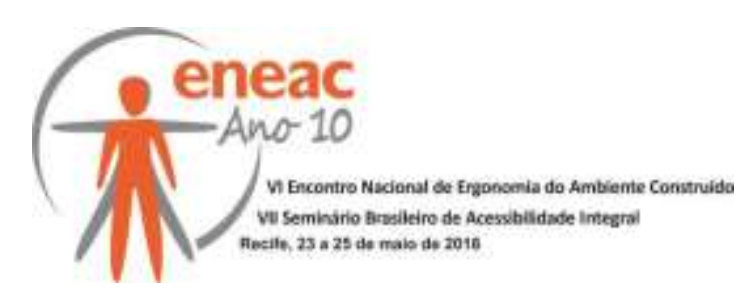

\section{CONSIDERAÇÕES FINAIS}

O CV se mostrou um edifício bem localizado no campus I da UFPB e com diversos atrativos, principalmente pelos diferentes usos que comtempla, sendo propício ao encontro e convívio social de usuários. Porém a QA do local apresenta-se deficiente para atender de modo adequado aos frequentadores, necessitando de atenção em diversos aspectos: iluminação artificial (muitas luminárias quebradas, com fiação exposta, e lâmpadas queimadas); infiltrações, muitas paredes com pichações e cartazes, necessitando de pintura, limpeza no local e em seu entorno; a permanência de seguranças, pois se trata de um espaço muito utilizado pelos usuários e com grande concentração de serviços; considerar a implantação de estacionamento específico para bicicletas e motocicletas, bem como, ampliar a sinalização do local e a rota acessível existente até a parada de ônibus mais próxima; realizar manutenção nos bebedouros e lixeiras (algumas estão quebradas); reativar os serviços da farmácia, dar uso aos pontos comerciais fechados; e trabalhar artisticamente a parede do corredor, que hoje se encontra servindo apenas para estacionamento irregular, de modo que as pessoas tenha interesse em circular pela área.

Desse modo, pode-se dizer que o CV apresenta grande potencial de utilização, com uma área considerável de EL e de serviços para a comunidade universitária da UFPB, porém indica-se, além da manutenção nos diversos aspectos citados, um maior rigor no uso do espaço, de modo que o comércio formal ou informal, novas edificações ou a ampliação de outras não venham a descaracterizar a edificação original, reduzindo a ventilação, iluminação, segurança e acesso proporcionado ao usuário, questões essenciais para uma vivência sadia no local. Nesse sentido, um maior cuidado com a ocupação do CV poderia significar uma maior qualidade para o SEL do campus e, sobretudo, mais qualidade de vida para seus usuários.

\section{REFERÊNCIAS BIBLIOGRÁFICAS}

BINS ELY, V. H. M.; GHIZI, D. M. Acessibilidade e Orientabilidade no Campus da Universidade Federal de Santa Catarina. In: $6^{\circ}$ Ergodesign. Anais... São Paulo: Bauru, 2006. Disponível em: < http://www.arq.ufsc.br/petarq/wp-content/uploads/2008/02/ergodesign-12.pdf >. Acesso em: 17 abr. 2011.

COSTA, A. D. L.; CEVADA, C. M.; VIANA, E.; RODRIGUES, J.; LIRA, R. Gestão do Solo Universitario: o Campus da UFPB no Brasil. In: $4^{\circ}$ Congresso Luso-Brasileiro para o Planeamento Urbano, Regional, Integrado, Sustentável, (Pluris 2010). Anais... Faro, Portugal: 2010.

COUTINHO, Marco Antônio Farias; ANDRADE, Patrícia Alonso de; VIDAL, W. C. L. Expansão no Campus João Pessoa da Universidade Federal da Paraíba: Entre o diálogo e a alienação. In: 3Docomomo N/NE, 2010, João Pessoa. Anais... João Pessoa: 2010.

CUSTÓDIO, V.; ARRUDA CAMPOS, A. C. de; MACEDO, S. S.; QUEIROGA, E. F. Espaços livres públicos nas cidades brasileiras. Revista Geográfica de América Central. Costa Rica, Número Especial EGAL, II Semestre 2011, p. 1-31.

GÜNTHER, H; ELALI, G. A.; PINHEIRO, J. Q. A abordagem multimétodos em Estudos PessoaAmbiente: características, definições e implicações. In: PINHEIRO, J. Q.; GÜNTHER, H. (Org.). Métodos de pesquisa nos estudos pessoa-ambiente. São Paulo: Casa do Psicólogo, 2008, p. 369396.

ISSA, M. P.; POLTRONIERI, J. P.; ORNSTEIN, S. W. Procedimentos para Avaliação Pós-Ocupação (APO) de Edifícios Escolares: O Caso da E.E. Fernando Gasparian, na cidade de São Paulo. In: NUTAU, 2008. São Paulo. Anais... São Paulo, 2008. Disponível em <http://www.usp.br/nutau/CD/82.pdf>. Acesso em: 31 mar. 2014. 


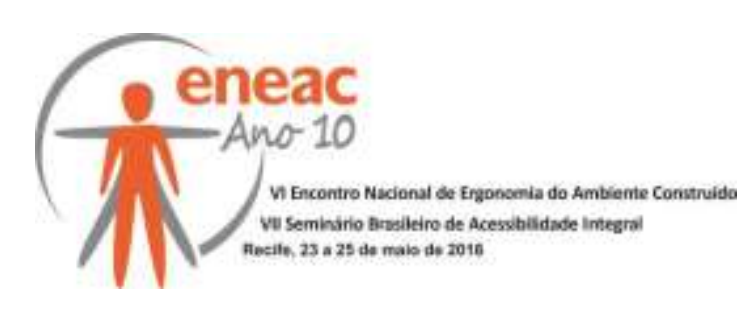

KOWALTOWSKI, D. C. K. ; MOREIRA, D. de C.; DELIBERADOR, M. S. O programa arquitetônico no processo de projeto: discutindo a arquitetura escolar, respeitando o olhar do usuário. In: SALGADO, M. S.; RHEINGANTZ, P. A.; AZEVEDO, G. A. N.; SILVOSO, M. M. (Orgs.). Projetos complexos e seus impactos na cidade e na paisagem. Rio de Janeiro: UFRJ/FAU/PROARQ; ANTAC, 2012.

MAGNOLI, M. M. Espaço Livre - Objeto de Trabalho. In: Revista Paisagem Ambiente: ensaios, $n$. 21.São Paulo: FAUSP, 2006, p. $175-198$.

ORNSTEIN, S. W.; ROMÉRO, M. (col). Avaliação Pós Ocupação do Ambiente Construído. SP: Studio Nobel, 1992.

PREISER , W.F. E.; VISCHER, J.C. Assessing Building Performance. Taylor \& Francis Group, 2005.

QUEIROGA, E.; MACEDO, S.; CAMPOS, A.C.; GONÇALVES, F.; GALENDER, F.; DEGREAS, H.; AKEMINE, R.; CUSTÓDIO, V. Notas gerais sobre os sistemas de espaços livres da cidade brasileira. In: CAMPOS, A.C.A.; QUEIROGA, E.F.; GALENDER, F.; DEGREAS, H.N.; AKEMINE, R.; MACEDO, S.S.; CUSTÓDIO, V. (Orgs.). Sistemas de espaços livres: conceitos, conflitos e paisagens. São Paulo: FAUSP, 2011. p. 11-20.

ROMÉRO, M.; ORNSTEIN, S.W. (Org.). Avaliação Pós-ocupação: métodos e técnicas aplicados à habitação social. Porto Alegre: ANTAC (Coleção HABITARE), 2003.

RHEINGANTZ, P. A.; AZEVEDO, G. A.; BRASILEIRO, A.; ALCANTARA, D. de; QUEIROZ, M.. Observando a qualidade do lugar: Procedimentos para a avaliação pós-ocupação. Rio de Janeiro: PROARQ, 2009.

SÁ CARNEIRO, A. R.; MESQUITA, L. de B. Espaços Livres do Recife. Recife: Prefeitura da Cidade do Recife/ Universidade Federal de Pernambuco, 2000.

SARMENTO, B.R.; ELALI, G.A. Os espaços livres sob o olhar do usuário: Um estudo no campus de uma universidade do Nordeste brasileiro. In: I Congresso Internacional Espaços Públicos. 2015. Porto Alegre. Anais... Porto Alegre, 2015.20 Disponível em <http://www.pucrs.br/eventos/espacospublicos/downloads/130_D.pdf>. Acesso em: 29 jan. 2016.

SARMENTO, B.R. Acessibilidade em sistema de circulação de pedestre: Avaliação do campus I da UFPB. Dissertação (Arquitetura e Urbanismo). Universidade Federal da Paraíba. João Pessoa-PB: 2012.

SOMMER, B.; SOMMER, R. A Practical Guide to Behavioral Research: tools and techniques. New York: Oxford University Press, 2002.

UNIVERSIDADE FEDERAL DA PARAÍBA (UFPB). Projeto UFPB - REUNI. João Pessoa: UFPB.2007. 